\title{
En la Onda de la Radio, de Bertha Lucía Arnedo.
}

Winston Morales Chavarro ${ }^{1}$

Docente de Tiempo Completo

Universidad de Cartagena.

Mi vida, como la de millones de seres humanos, está determinada, sin duda alguna, por lo que Marshall McLuhan llamaría la Galaxia Marconi o la Aldea Cósmica.

A comienzos de los años 70 -nací en 1969- todo estaba atravesado ya no por la lógica de lo oral o lo escrito, sino por los hilos delgados de los viejos RCA que se erguían orgullosos en las salas de las familias más adineradas de Neiva. La transmisión de señales mediante la modulación de ondas electromagnéticas se constituía ya en un referente del nuevo mundo

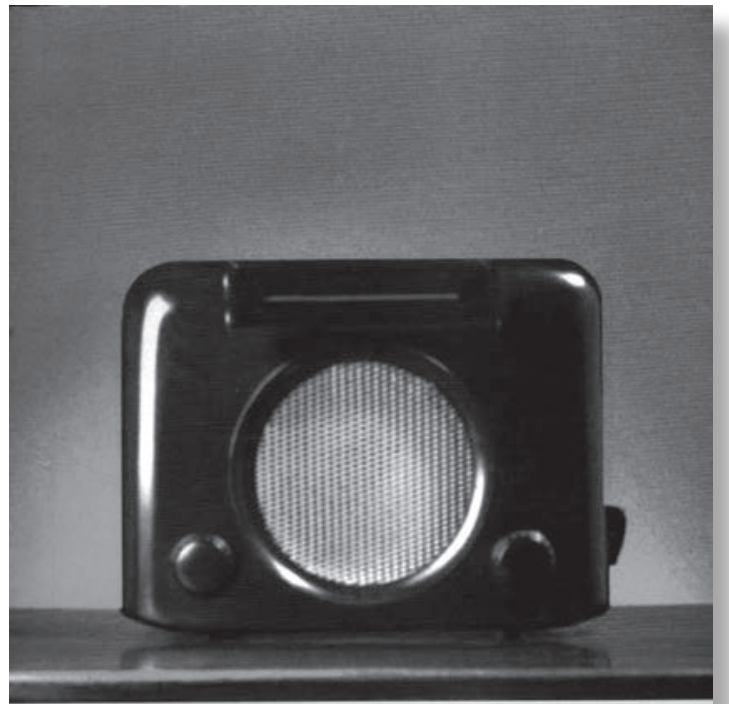

En la Onda de la Radio

Historia, Diseño y Producción Radial que comenzábamos a caminar. Si nuestros padres aún conservaban la sazón que le daba a la vida la oralidad, nosotros, los niños de los 70's, poníamos una mirada de asombro al universo caliente de las emisoras. Y digo caliente porque para nosotros eso era la radio: medio de grandes temperaturas.

Mi primer contacto con la radio se lo debo a mi padre: era un restaurador de cuanto cachivache eléctrico llegaba a la casa. En sus años de juventud reparaba ajados radiotransistores, radiolas y lo que, a manera de burla, denominábamos Sanyo Panelas, primos octogenarios de los Mp3 y Mp4. Gracias a él supe de la existencia de Yaco Monti, Sandro, Palito Ortega y Enrique Guzmán, hombres que luego me recordarían los orígenes del rock en español en países como Argentina y México. Posteriormente sabría de Kalimán, Solución a su problema y La ley contra el hampa, programas que escuchaba una señora a la que visitaba todas 
las tardes para que corrigiera mis falencias con los números; la profesora se detenía en mitad de la operación para escuchar la voz estentórea de Kalimán (Gaspar Ospina) o el acento monorrítmico de Solín (Erika Krum).

La radio estuvo a mi lado siempre. Luego la televisión, pero la radio era como una estría, una gran cicatriz en el pecho. Ya mucho más grandecito me conecté con una emisora que sería fundamental para muchos jóvenes en los años 80: Radio Tequendama. A través de Radio Tequendama, mucho antes de 88.9 o Radio Activa, arribamos al heavy metal: Def Leppard, Van Halen, Black Sabbath o Led Zeppelin.

La radio ha sido determinante para un gran porcentaje de la población mundial que nació entre 1930 y 1990 . Incluso, me atrevería a pensar que pese a esa aldea cósmica de la que nos hablara McLuhan, la radio sigue siendo preponderante aún en nuestros días: se debate victoriosa, luego de que muchos profetas pronosticaran su fin, entre las redes sociales, la telefonía celular, la televisión satelital o el gigante estúpido: Facebook.

De eso nos habla Bertha Lucía Arnedo en su bello libro En la Onda de la Radio. Ella, al igual que millones de Homo Consumus (llámese hombre), le debe su vida a la radio. Todo lo que es, o casi todo, nace y termina en el medio. Y ante esas deudas colosales, Bertha Lucía siente la necesidad de pagarle con creces a uno de los medios calientes que perviven pese a sus más de cien años de existencia. De allí viene su libro, de esa retribución coherente con lo que es su oficio como docente universitaria. Bertha, y de eso pueden dar fe todos sus condiscípulos, ama el medio, ama la radio, ama los micrófonos. Para quienes amamos la radio, como sé que la ama ella, el medio no es solo el mensaje: la radio es incluso lo inexpresado, el silencio, lo que se calla. Pero es también la vida, atmósfera, sustancia, aceite para las ruedas por las que circula el mundo.

En la Onda de la Radio es un bello libro que nos habla de los antecedentes históricos de la Radio, de esos prohombres que como Aleksandr Stepánovich Popov, James Clerk Maxwell, Heinrich Hertz (de él viene el término ondas hertzianas), Nikola Tesla, Guillermo Marconi o Julio Cervera Baviera (de quien se dice es el verdadero inventor de la radio), fueron fundamentales en la aparición del medio.

Muchas veces me he preguntado que hubiera sido de la música o de los grandes compositores sin la aparición de la radio. Seguramente seguirían 
vigentes, como lo hicieron en su momento Bach, Beethoven, Chopin o el mismo Chaikovski, pero ipodríamos hablar de un proceso democrático de la música y otras manifestaciones del mundo interior del ser humano sin la radio? Sin duda alguna la radio en la vida de la gente fue una especie de motor hacia consideraciones de carácter político, social y cultural. Y de todo esto nos habla Bertha Lucía en la radio en la vida de la gente: las transformaciones mentales, los impactos socioculturales, las lógicas hiperindividualistas de los nuevos sonidos, los imaginarios sociales que se ven seriamente mediados por las dinámicas sonoras de uno de los inventos más prodigiosos de todos los tiempos: de eso nos deja constancia la película británica El Discurso del Rey, dirigida por el casi adolescente Tom Hooper.

En la Onda de la Radio se nos habla de las radios alternativas en Colombia; la Radio Cultural; la significación de la Radiodifusura Nacional de Colombia y la HJCK, fundada esta última por Álvaro Castaño Castillo el 15 de septiembre de 1950. De la HJCK recuerdo las "Colecciones literarias H.J.C.K.", iniciadas en 1960 con "El sueño de las escalinatas" de Jorge Zalamea, y las lecturas poéticas de vates como Jorge Luis Borges, Álvaro Mutis, León de Greiff, Eduardo Cote Lamus o Raúl Gómez Jattin. Eran tiempos dorados en la Radio colombiana.

Bertha Lucía además de la escritura de un libro, parece manejar en su camino bibliográfico un autobús de 16 ruedas. A través de ese viaje vamos recorriendo no sólo la historia de la radio, sino también la historia de la radio en Cartagena, los impactos de ella en el siglo XXI, y hace una categorización de las emisoras, recordándonos la clasificación de emisoras comerciales, de interés público (como nuestra Udec Radio) y las comunitarias.

En resumen, es un libro relevante para comprender e interiorizar el mundo maravilloso de la radiodifusión. Un libro que se constituye en texto de consulta para nuestros jóvenes universitarios, ávidos de información en cuanto al medio se refiere, y libro histórico porque se ocupa de los procesos fundacionales en una ciudad tan importante para el medio como lo ha sido Cartagena de Indias.

Hojeando En la Onda de la Radio, rememoro aquellos pasajes de la vida en donde la radio era un fenómeno tan significativo en las esferas privadas y públicas del hombre contemporáneo. Entonces pienso en la adaptación para radio que Orson Welles y el Teatro Mercurio hicieron de La guerra de los mundos, novela de ciencia ficción del gran escritor e historiador británico 
Herbert George Wells, y que causó gran conmoción en Nueva York y en Nueva Jersey, ya que un alto porcentaje de la población creyó que en realidad se trataba de una invasión extraterrestre. Pienso en los tiempos del cantante brasilero Orlando Silva, cuando fue declarado El Rey de la Radio Nacional de Brasil, en momentos en que un locutor podía convocar a todas aquellas personas que tuvieran vehículos para que se parquearan en los costados de un gran potrero, y con sus luces improvisaran una rústica carretera que sirviera de pista de aterrizaje para un avión que se encontraba en apuros. Rememoro a Woody Allen en Días de Radio, película de 1987 que recrea el encuentro de Allen con el jazz en 1940. Y pienso también en El Bogotazo, en las implicaciones que tuvieron muchos locutores al fomentar la salida masiva a las calles de cientos de adeptos del caudillo Jorge Eliecer Gaitán. Pienso en la gran asonada que causó la información irresponsable de un par de borrachos que luego de un partido de fútbol entraran gritando a Neiva, procedentes de Yaguará, que la represa de Betania se había quebrado, lo que obligó a que muchos locutores prendieran las alarmas, generando una estampida sin precedentes en la ciudad.

Todo esto lo hizo la radio. Todo eso lo ha fomentado la radio. Y hasta males nos ha ocasionado la pequeña caja de pandora. Prueba de ello son los muchos alcaldes que han surgido en ciudades como Medellín, Neiva, Barranquilla y Cali, amparados en la retórica populista de quienes manejan el micrófono. Espero que Cartagena sea la excepción.

Gracias a Bertha por este maravilloso libro. Gracias a ella por darse a la tarea de recuperar ciertos momentos gloriosos de la radio cartagenera. Gracias por fomentar el estudio en la memoria de un medio que sigue tan vigente pese a las nuevas tecnologías y a la aparición casi fantasmagórica del gigante estúpido: las redes sociales. Estamos en tiempos de radio. Brindemos por ella. 